\title{
Partidos de ámbito no estatal e integración europea. Los casos de Convergència i Unió, el Scottish National Party y la Lega Nord
}

\section{Cesáreo Rodríguez-Aguilera de Prat}

Universidad de Barcelona

rodriguezaguilerade@ub.edu

\section{Resumen}

Este estudio compara las posiciones programáticas de tres PANE sobre los grados más o menos convenientes de integración europea desde sus posiciones respectivas. Se analizan tres dimensiones vinculadas a la naturaleza de la UE, la noción de "ciudadanía europea» y el alcance otorgado por cada uno de ellos a la integración en las políticas de los tres pilares comunitarios. La comparación reviste interés por tratarse de tres PANE de perfiles ideológicos distintos, que, además, están integrados en eurogrupos diferentes en el Parlamento europeo. Se constata que $\mathrm{CiU}$ presenta una mayor vocación supranacional (con algunas singularidades), mientras que el SNP se aproxima a una visión confederal y la LN se muestra crecientemente euroescéptica.

Palabras clave: estrategias europeas de los partidos de ámbito no estatal, integración europea, programas para las elecciones europeas.

Abstract: Non-State wide parties and European integration. The cases of Convergència i Unio, the Scottish National Party and the Lega Nord

This research compares the programmatic positions of three non-State wide parties regarding the degrees to wich European integration is more or less acceptable. Three dimensions of the EU nature, the concept of «European citizenship» and the significance conferred of each dimensions in order to integrate in the policies of the three communitarian pillars are analyzed. The comparison is interesting because there are three parties with different ideological profiles and also there are integrated in different Eurogroups in the European Parliament. In conclusion: $\mathrm{CiU}$ offers a big supranational vision (with some peculiarities), while the SNP is nearer to a confederal vision and the LN is increasingly eurosceptical.

Key words: European strategies of non-State wide parties, European integration, European electoral manifestos. 


\section{Sumario}

\section{Presentación}

1. Sobre la naturaleza y el espacio territorial de la UE

2. Ciudadania europea y cuestión de los extracomunitarios

\section{Instituciones y políticas}

Conclusiones provisionales

Obras de referencia sobre los partidos analizados

\section{Presentación}

Este estudio forma parte de una investigación comparada en curso mucho más amplia, centrada en el análisis de los programas que los principales partidos representativos (se han seleccionado treinta y cinco) de los seis estados más poblados de la UE (Alemania, Francia, Reino Unido, Italia, España y Polonia) presentaron a las elecciones europeas de $2004^{1}$. El objeto central de la misma es el de analizar de modo transversal las posiciones de los partidos y las familias de partidos (integrados en los eurogrupos del Parlamento europeo) en issues relacionadas con las dimensiones que inciden en la configuración de la UE como eventual sistema político integrado por los clásicos elementos de territorio, pueblo y poder. Es decir, se trata de calibrar hasta qué punto los partidos están dispuestos o no a ceder parcelas de soberanía en los ámbitos territoriales de toma de decisiones y de regulación institucional, a la vez que concretar tales dimensiones en las propuestas políticas para los tres pilares. Más exactamente, el proyecto en curso describe y analiza: 1) las posiciones de los partidos a propósito de su concepción global de lo que es y debería ser la UE (supranacionalismo versus intergubernamentalismo) y sus eventuales propuestas sobre las fronteras exteriores definitivas; 2) la noción sustantiva o adjetiva de la "ciudadanía europea», cuestión vinculada al concepto respectivo de "cultura común» (lo que afecta al debate sobre las «raíces cristianas»), además de incidir en las actitudes hacia los extracomunitarios, y 3) las posiciones ante el Tratado Constitucional (TCUE) y las reformas institucionales comunitarias, así como las propuestas de políticas públicas sectoriales en economía y sociedad, política exterior y de defensa y cooperación policial y judicial.

En este artículo, se han segregado del proyecto global los apartados dedicados a tres PANE muy significativos — a la vez que se han interrelacionado—, para

1. En esta investigación, se ha optado por no cuantificar al modo del Comparative Manifestos Project los items seleccionados, pues su eventual formalización cuantitativa no es el objetivo cualitativo perseguido en la misma. No aportaba evidencias de especial relieve en este proyecto acumular las diversas referencias programáticas de los partidos, pues el planteamiento escogido es antes de análisis interpretativo comparado que de operacionalización técnica de diversos items, de ahí la elaboración de una plantilla propia de cuestiones que se visualiza en los gráficos sectoriales. Esto no quita que la aportación de I. Budge y otros sea de gran interés específico: «Mapping Policy Preferences: 21 Years of the Comparative Manifestos Project», ECPR-EPS, n.o 1.3, verano de 2002. Vid. asimismo RodríGUEZ-AGUILERA, C. Partidos políticos e integración europea. Barcelona: ICPS, 2008, p. 77-80. 
insertarlos en la propuesta de trabajo del grupo de investigadores dirigido por la profesora Montserrat Baras (UAB). Concretamente, se comparan los programas europeos de CiU, el SNP y la LN, de 2004, lo que tiene un doble interés científico: 1) de un lado, se pone de relieve que el carácter estructural de PANE no predetermina en absoluto sus preferencias ideológicas y 2), de otro, que sus posiciones ante la UE son heterogéneas, pues, en los tres casos seleccionados, se constata que hay notorias divergencias entre ellos, además de estar integrados en tres eurogrupos diferentes. Así, cabe ubicar a CiU en el espacio ideológico del centro-derecha; al SNP, en el del centro-izquierda, y a la LN, en el de la derecha populista. En el otro sentido, es constatable que CiU presenta una mayor preferencia europea integracionista (no sin algunas particularidades), el SNP mantiene tesis bastante clásicas de corte confederal y la LN - que podría encajar en esta preferencia- es, de las tres, la formación que más reservas aduce frente a la UE.

\section{Sobre la naturaleza y el espacio territorial de la UE}

$\mathrm{CiU}$, que es miembro del eurogrupo (y europartido) Alianza de los Demócratas y Liberales Europeos, presenta una posición un tanto singular en el mismo, precisamente por su carácter de PANE con reivindicaciones etnoterritoriales muy específicas ${ }^{2}$. En su programa europeo, CiU afirma que «la UE no puede ser sólo un gran mercado, ni tampoco puede ser sólo una unión política», pues — a su juicio - la clave está en otra dimensión, la etnoterritorial: «la construcción europea no se conseguirá plenamente si no hay un verdadero reconocimiento de la realidad plurinacional de Europa ${ }^{3}$. La estrategia de CiU es la de «tener la máxima fuerza política posible para ser la [sic] voz de Cataluña y de los catalanes [singular distinción que no se aclara] en Europa», pues esta formación aspira a liderar la "afirmación nacional de Cataluña en Europa», así como a representar los valores y los intereses de esta comunidad en la UE. Típico planteamiento nacionalista en todos los sentidos: 1 ) «ir a Europa» a reivindicar intereses nacionales y 2) ser la expresión privilegiada (sino incluso de vocación única) de Cataluña como un todo que supuestamente compartiría unos mismos valores y tendría intereses comunes similares. A partir de esta afirmación inicial, el planteamiento de $\mathrm{CiU}$ es el de la plena defensa de Cataluña en Europa, el reconocimiento de Cataluña como nación europea, el derecho de Cataluña a participar directamente en las decisiones de la UE o la reivindicación del catalán como lengua oficial de ésta. Para CiU, la UE es un conjunto de pueblos diversos, muchos de ellos con «clara vocación identitaria», aunque

2. Como es sabido, Convergència Democràtica de Catalunya es miembro del eurogrupo liberal desde el ingreso de España en la Comunidad Europea, mientras que Unió Democràtica de Catalunya - el histórico partido democristiano catalán — se integró en el eurogrupo popular. La incorporación posterior del Partido Popular español a este eurogrupo acabó ocasionando el abandono de UDC del mismo y su pase al liberal.

3. CiU: Una nova Europa ampliada oberta a les persones $i$ al món, 2004. 
sin proporcionar criterios objetivos para saber quién, cómo y por qué determina tal distinción entre pueblos. Sobre las fronteras últimas posibles de la UE, CiU se limita a formular una doble afirmación: «la UE no puede crecer indefinidamente» y habrá que establecer nuevas políticas de Wider Europe que permitan ofrecer nuevos sistemas de relación permanente y estable con los países vecinos que no pasen por la integración (una probable referencia indirecta a Turquía).

El SNP está integrado en un eurogrupo dual (Partido Verde Europeo-Alianza Libre Europea), cuya principal razón de ser es precisamente la de reivindicar la «Europa de las naciones sin Estado» ${ }^{4}$. De entrada, este partido afirma que el verdadero poder en la UE recae en los estados puesto que sus entidades internas cuentan poco o nada a nivel comunitario ${ }^{5}$. A continuación - hecho este diagnóstico- - tal partido reclama el derecho a la plena soberanía de Escocia: «nosotros creemos que asuntos como la Constitución nacional o nuestro sistema impositivo deben permanecer bajo control nacional». El SNP señala que la UE es muy útil para los estados pequeños (como Irlanda, Dinamarca o Austria) — que son los que más se desarrollan (una afirmación que, con carácter general, cabría matizar tras la incorporación de varios PECO)—, una tesis esgrimida para reforzar su estrategia independentista. A ello añade que «los estados pequeños tienden a ser más flexibles y pueden adoptar a menudo sus posiciones negociadoras más fácilmente» (a veces es todo lo contrario), sin mencionar el problema derivado del incremento del número de miembros a propósito de la creciente complejidad y dificultad de los procesos decisionales. A continuación, el SNP hace una doble afirmación indemostrable, prototípica como partido nacionalista: 1) es el partido que mejor defiende los intereses de Escocia y 2) la independencia (siempre con el añadido «en Europa») cambiará para mejor las vidas de los ciudadanos escoceses. Y es que el proyecto europeo del SNP es claramente confederal y no federal, pues se basa en la tesis de sustituir a los actuales estados naciones por nuevos estados (más numerosos) que representen a las verdaderas naciones. Su planteamiento es, pues, nacionalista y no federalista, ya que aspira a estar presente en los dos consejos comunitarios como estado, con capacidad para vetar medidas que lesionen los intereses del país y para impedir interferencias en determinadas políticas (por ejemplo, la pesquera). En suma, «el SNP cree en una UE como confederación de estados» y

4. Se trata de un caso singular en el PE: en este único eurogrupo conviven dos europartidos, el de los Verdes y ALE. Pese a pertenecer a familias de partidos bastante diferentes, tal fórmula parece bien consolidada. Sobre ALE como intento — sólo parcialmente conseguidode integrar a los partidos nacionalistas subestatales, véase LYNCH, P. «Co-operation between regionalist parties at the level of the European Union. The European Free Alliance». En: L. DE WinTER y H. TÜRSAN (eds.). Regionalist Parties in Western Europe. Londres: Routledge, 1998, p. 190 y s. Asimismo, LYNCH, P. «Le délitement du regionalisme suite à l'elargissement de l'Europe? Le futur de l'Alliance libre européenne-PDPE». En: P. DELWIT (ed.). Les partis régionalistes en Europe. Des acteurs en développement? Bruselas: Éditions de l'Université de Bruxelles, 2005, p. 85 y s.

5. European Manifesto, 2004. 
rechaza una mayor integración, por ver en ello el peligro potencial de un nuevo centralismo y una eventual amenaza para la identidad nacional. En cuestión de fronteras, el SNP aprueba la ampliación a los PECO, pero añade interesadamente que si Malta es un estado, ¿por qué no Escocia?

La LN está a favor de "una Europa que sea una libre asociación de pueblos», con pleno reconocimiento de la soberanía de cada uno y, por tanto, del derecho de autodeterminación de los mismos ${ }^{6}$. Esta formación puede aceptar ciertos vínculos paneuropeos, a condición de que estén subordinados a los intereses de los pueblos existentes. Un planteamiento que combina elementos doctrinales característicos de los partidos nacionalistas subestatales con otros de corte populista, y ambos con límites muy claros a la integración europea: «la LN considera indispensable que los Pueblos [sic] conserven la capacidad de expresar y obtener la rescisión de la adhesión a la UE». En este sentido, este partido rechaza la eventual federalización europea, un proyecto supuestamente fruto «de instituciones internacionales tecnocráticas y alejadas de nuestra especificidad territorial de imponer un modelo de sociedad contradictorio con relación a nuestros valores y nuestra cultura». La LN rechaza la hipótesis de un superestado europeo, pues ello supondría imponer un centralismo "guiado por tecnócratas políticamente irresponsables», sin aportar ningún dato que avale este desenlace predeterminado. A su juicio, la federalización de la UE respondería a un oscuro proyecto globalizador, expresión del «pensamiento único» (no se aclara cuál podría ser éste), muy en consonancia con su visión populista y conspirativa de la realidad: «el pensamiento único, financiado y guiado por los intereses mundialistas, es un artificio virtual que niega la historia, ya que quiere hacer instrumentalmente súbditos suyos a sus pueblos soberanos». En suma, la LN rechaza las políticas que buscan favorecer la armonización de los diversos sistemas jurídicos, pues ello «comportaría la anulación del principio subyacente de toda realidad confederal: el mantenimiento de una pluralidad de entidades constituyentes, con su propia identidad histórica, política, cultural y jurídica», con lo cual manifiesta el horizonte máximo infranqueable de la UE para esta formación, que es el de la confederación de pueblos soberanos.

En cuestión de fronteras exteriores, la LN dedica de modo monotemático una especial atención al caso de Turquía, a cuya candidatura este partido se opone frontalmente. En efecto, a su juicio, el trato que este país da al Kurdistán o la ocupación del norte de Chipre (dos ejemplos no por casualidad referidos a la cuestión nacional) basta para descartar del todo su petición de ingreso, por no mencionar la falta de reconocimiento oficial del genocidio armenio. Además, la tutela militar es inaceptable, la reislamización de la sociedad turca constituye un paso atrás peligroso para Occidente y la economía de ese país está demasia-

6. LN: Programma per le elezioni europee, 2004. La LN estuvo integrada en el eurogrupo (que no europartido) Independencia y Democracia, de marcado cariz euroescéptico (uno de sus principales miembros es, por ejemplo, el United Kingdom Independence Party, que reclama la salida del Reino Unido de la UE). La LN se integró después en el eurogrupo Unión de la Europa de las Naciones (que asimismo incluye a diversos partidos euroescépticos), en enero de 2007. 
do atrasada. Para la LN, "Turquía, histórica y culturalmente, no es europea» y como eventual país miembro de la UE desplazaría a Alemania del primer lugar y tendría más europarlamentarios que cualquier otro estado, un escenario del todo indeseable desde su perspectiva. En suma, esta formación sostiene la necesidad de «considerar criterios históricos, culturales y religiosos para regular el proceso de ampliación de la UE», unos parámetros que no están contemplados en absoluto por los acuerdos comunitarios al respecto (los de Copenhague).

En estas cuestiones, para $\mathrm{CiU}$ el verdadero dilema no radica en optar entre una visión supranacional o intergubernamental de la construcción europea, sino en conseguir el pleno reconocimiento de su plurinacionalidad interna más allá de los estados. Aunque no se define con precisión sobre el alcance último deseable de las fronteras exteriores de la UE, CiU asume que este asunto deberá abordarse con la perspectiva de alcanzar un acuerdo global de cierre, y esto es lo que le permite mantener una ambigüedad calculada sobre Turquía.

El SNP mantiene una visión en el fondo muy clásica sobre la construcción europea, porque su horizonte es estrictamente confederal e intergubernamental y, aunque aprueba la ampliación a los PECO, no se pronuncia sobre los posibles límites finales de la UE, aunque añade que el ingreso de pequeños estados hace más injustificable que se niegue a sus naciones el derecho a ser estados. No hay la menor referencia a Turquía, un asunto que está muy lejos de las preocupaciones de este partido, si bien - muy en sintonía con las percepciones británicas, aunque esto no pueda admitirlo - el SNP no tiene la menor objeción de fondo a tal candidatura.

De modo relativamente similar, también la LN tiene una visión confederal y estrictamente intergubernamental de la UE. En su perspectiva, la clave es asegurar a los pueblos sus intereses, todo muy en consonancia con su tradicional egoísmo socioterritorial y con su orientación populista. Además, es la formación más contraria a seguir ampliándola indefinidamente y, sobre todo, es frontal su rechazo a la candidatura turca.

\section{Cuadro 1}

UE supranacional

UE intergubernamental

UE «tercera vía»

Ampliar la UE sin fijar límites

Ampliar con la perspectiva de limitar

Turquía en la UE

Turquía fuera de la UE

No consta
SNP, LN

$\mathrm{CiU}$

SNP

CiU, LN

LN

CiU, SNP

\section{Ciudadanía europea y cuestión de los extracomunitarios}

En principio, CiU se muestra favorable a una «amplia definición del concepto de ciudadanía europea», sin mayores precisiones. En este ámbito, sobresalen dos preocupaciones, una lingüística y otra étnica: en el primer caso, CiU recla- 
ma la oficialidad del catalán en la UE, el apoyo a las lenguas minoritarias y el desarrollo de las capacidades lingüísticas de los europeos, con la potenciación del aprendizaje de lenguas comunitarias. En el segundo, CiU da un pleno apoyo a políticas natalistas autóctonas que incentiven las familias numerosas, pues manifiesta recelos frente a los extracomunitarios como mecanismo compensador del envejecimiento de la población europea, al insinuar dificultades de integración en los valores europeos. Y es que, en esta dimensión, la política de CiU está llena de reservas: de entrada, se reclama una política común, con una gestión «bien integrada en el seno de una política económica y social comunitaria moderna», lo que coloca ciertos intereses como prioritarios ante los derechos de los extracomunitarios como personas. A continuación, se añade: «hay que aplicar, desde el realismo, una política común de inmigración", lo que implica —en su perspectiva - optar por cupos restrictivos. Por lo demás, aunque se aspira a la integración "activa» de los extracomunitarios, $\mathrm{CiU}$ sólo menciona expresamente los derechos laborales y su predisposición a respetar la identidad de aquéllos. Los derechos laborales son, sin duda, claves para tales colectivos, pero insuficientes en sí mismos para conseguir una plena integración activa, tal como se preconiza. Por lo demás, es correcto respetar identidades, siempre que no generen guetos separados a modo de compartimentos estancos y, mucho menos, que supongan discriminación para algunos de sus miembros (notoriamente, las mujeres en determinados grupos extracomunitarios que residen en la UE).

El SNP afirma compartir el proyecto de una Europa que promueva su diversidad cultural y lingüística, en el bien entendido de que la clave es el pleno respeto de la identidad de cada una de las naciones que la integran. Aunque en su manifiesto europeo no menciona ni de pasada a los extracomunitarios (algo totalmente asumido como normal por la gran mayoría de los partidos británicos), debe reseñarse que el SNP es un partido radicalmente opuesto a la xenofobia y cuyo nacionalismo - antes cívico que étnico- es integrador y abierto.

La LN tiene una concepción localista cerrada de la ciudadanía: las identidades culturales etnoterritoriales deben preservarse a toda costa y la UE debe favorecer modelos que respondan a las exigencias estrictas de cada comunidad para defender sus rasgos singulares. Su apuesta por una Europa de los valores tiene una acentuada dimensión integrista e islamófoba: «el primero de ellos, el valor cristiano: precisamente cuando a escala global se manifiesta el terrorismo de matriz islámica, con toda la ferocidad que le contradistingue, es fundamental remarcar con fuerza la identidad europea que se funda en tal valor». En consecuencia, no pueden sorprender las restrictivas y xenófobas propuestas de la LN, pues, de un lado, preconiza limitar al máximo el ingreso de extracomunitarios en la UE — toda vez que el mercado de trabajo debe reservarse, a su juicio, a los ciudadanos europeos, con criterios de preferencia nacional (al modo del Front National francés) — y, de otro, se muestra contraria a la política de la Comisión, que ha apostado por una legislación antirracista (con lo que cabe deducir que la LN optaría por dejar impune el racismo) y por unas directivas que consolidan e imponen [sic] la sociedad multicultural. Para este par- 
tido, esta política respondería a intereses «espúreos» de algunos políticos y de grandes corporaciones económicas y así, con una argumentación de tipo conspirativo muy propia del populismo, afirma: "gracias a la cortedad de miras de políticos falsamente buenistas que han abierto las puertas a cientos de miles de extracomunitarios, ha sido posible para los terroristas islámicos crear una red invisible o casi de células incontrolables dispuestas a llevar muerte y destrucción a los países occidentales y no sólo a ellos».

$\mathrm{CiU}$ presenta posiciones de difícil encaje en la dicotomía entre pueblo europeo y pueblos de los estados, pues su perspectiva nacionalista subestatal introduce, con carácter preliminar, el reconocimiento de lo que esta formación reputa como las verdaderas naciones antes de dilucidar los contenidos posibles de la ciudadanía europea. Al final, no deja de ser un tanto llamativo que CiU no haga referencia en su programa a las «raíces cristianas» de Europa, teniendo en cuenta que uno de los dos partidos que integran tal federación es democristiano: probablemente la inclusión de UDC en el eurogrupo liberal le ha llevado a congelar esta reivindicación. En materia de presencia de extracomunitarios en la UE, CiU no se opone, pero reclama algunas condiciones para asegurar una convivencia aceptable.

Del manifiesto del SNP, no se deduce que este partido apueste por ir configurando un demos europeo, pero tampoco parece reputar la ciudadanía europea como un mero formalismo nominal. Su preocupación, como partido nacionalista, es antes la de construir su propia nación, sin rechazar el complemento europeo. No hay la menor referencia al cristianismo, como partido laico que es, ni tampoco es muy explícito a la hora de pronunciarse sobre qué modelo de sociedad europea debería ser el más conveniente. En todo caso, el SNP está abierto a la recepción de inmigrantes extracomunitarios con vocación integradora.

Es la LN la que presenta el mayor rechazo de cualquier noción de pueblo europeo, de ahí que reduzca la definición de ciudadanía europea a una mera formalidad secundaria. Es también este partido el único de los tres que hace del cristianismo un elemento definidor central y excluyente de lo que deba entenderse por "cultura europea» $y$, en este sentido, muestra una intensa xenofobia al rechazar el modelo de la sociedad multicultural, reputado destructivo de las identidades naturales de los pueblos. En consecuencia, es congruente que sea el partido más opuesto a la continua recepción de nuevas oleadas de inmigrantes extracomunitarios.

\section{Cuadro 2}

Ciudadanía Europea = demos común

Ciudadanía Europea $=$ formalidad nominal

Ciudadanía Europea $=$ complemento

Cultura Europea $=$ raíces cristianas

Cultura Europea $=$ sociedad multicultural

No consta

Facilitar presencia de extracomunitarios

Limitar presencia de extracomunitarios
LN
CiU, SNP
LN
SNP
$\mathrm{CiU}$
SNP
CiU, LN 


\section{Instituciones y políticas}

\subsection{Las propuestas de reforma institucional}

$\mathrm{CiU}$ es favorable a una constitución para Europa que reconozca las libertades de los ciudadanos y los pueblos y, aunque el TCUE no le resulta del todo satisfactorio - sobre todo en el segundo sentido-, es reputado como un paso globalmente positivo. Esta formación propone convertir a la Comisión en el verdadero ejecutivo de la UE, hacer más transparente al Consejo de Ministros, reforzar al PE para acercarlo a los ciudadanos y transformarlo en el legislativo y otorgar al Tribunal de Justicia funciones de Tribunal Constitucional. Por supuesto, como formación nacionalista subestatal que es, CiU está interesada en potenciar el Comité de las Regiones, del que habría que cambiar su composición y su modo de elección, así como aumentar significativamente sus poderes; en particular, reconociendo la posibilidad de recurrir ante el Tribunal de Justicia. En este capítulo, CiU opta por un regionalismo diferencial - muy en consonancia con su visión asimétrica del autonomismo-, al reclamar más poderes para las «naciones sin estado». Es decir, CiU afirma que las regiones europeas con "personalidad nacional» deben tener un estatus especial en las instituciones comunitarias. Puesto que es por definición discutible dilucidar qué territorio posee o no una "personalidad nacional», CiU se acoge a un cierto criterio objetivable: se trata de que las regiones europeas con poder legislativo propio tengan una consideración particular en el Comité de las Regiones, pero no propone ninguna fórmula para traducir tal singularidad cuantitativa y cualitativamente. Al referirse a Cataluña, CiU defiende que esta comunidad tenga "Voz propia» en la UE, lo que debería significar — a su juicio- poder participar directamente como tal en el Consejo de Ministros, además de ser circunscripción electoral específica.

De entrada, el SNP reconoce que algunos asuntos se gestionan mejor a nivel comunitario que estatal o subestatal: protección medioambiental, igualdad de oportunidades, lucha contra la pobreza, erradicación de algunas enfermedades, protección de menores o cooperación policial. Sin embargo, como partido nacionalista subestatal, su prioridad es la de arrancar una interpretación regional del principio de subsidiariedad mientras no sea posible acceder al estatus de estado independiente. El SNP no apoyó el TCUE porque, desde su perspectiva, algunos intereses escoceses se habrían visto rechazados y porque la mediación británica habría sido muy poco sensible al respecto. Más en particular, el SNP acusa a Bruselas y Londres de perjudicar a Escocia en el capítulo de la industria pesquera. Además, la presencia del Gobierno escocés en el Consejo de Ministros de la UE sería marginal y mínima: a juicio del SNP, apenas en el $10 \%$ de los casos y sólo una vez en cinco años en un asunto clave para Escocia. Incluso llega a afirmar — contra toda evidencia - que la situación actual es peor que antes de la devolution: algo del todo inverosímil, pues basta recordar las muy duras críticas del SNP al nacionalismo gran-inglés y al hipercentralismo de la Premier tory Margaret Thatcher. Su conclusión es contundente: los intereses de Escocia no se defienden bien a través del Reino 
Unido, de ahí la necesidad de ser independientes. Con la independencia, afirma el SNP, Escocia tendría "voz propia» para defender sus intereses, una concepción instrumental y típicamente nacionalista de la UE. Con la independencia - argumenta el SNP_, Escocia tendría su comisario y más europarlamentarios (catorce en vez de siete), pero estas previsiones están destinadas a ser algo del pasado, pues las propuestas más sólidas de reforma institucional comunitaria van en la dirección de acabar con el principio de un comisario por estado y de frenar (e incluso reducir) la política de incrementar constantemente el número de eurodiputados tras cada ampliación.

En éste ámbito, el programa de la LN hace tres tipos de consideraciones: rechazo de reformas que puedan favorecer la federalización de la UE, estricto confederalismo y subsidiariedad regional reforzada. En el primer caso: «la LN afirma que la UE no tiene su razón de ser en reproponer un modelo centralista», pues "debe poner en primerísimo plano la soberanía del pueblo que prevalecerá con relación a cualquier tipo de élite no democráticamente elegida». En el segundo caso, se defiende nada menos que todos y cada uno de los estados tenga dos comisarios, una hipótesis que haría totalmente inmanejable e inoperante tal institución. Además, la LN defiende el mantenimiento del principio de unanimidad en todos los procesos decisionales comunitarios, un mecanismo absolutamente paralizador llevado hasta las últimas consecuencias. De acuerdo con esta visión confederal, se añade que «cualquier norma europea que directa o indirectamente viole un principio o un valor constitucional de un estado deberá ser considerada nula, ya que, en caso contrario, se violarían los principios de soberanía popular y del Estado de Derecho». Por último, la LN reafirma el valor del principio de subsidiariedad regional como eje clave para proporcionar la mayor seguridad a los pueblos. A su juicio, la «Europa de las Regiones», más próxima a los ciudadanos, debe primar sobre tecnócratas anónimos y élites no elegidas, muy en consonancia con su discurso populista.

$\mathrm{CiU}$ es favorable al TCUE y, en consecuencia, a incrementar los actuales poderes de las instituciones comunitarias, en la línea de avanzar hacia una verdadera división de poderes horizontal que visualice con claridad la existencia de un ejecutivo, un legislativo y un judicial comunitarios. Asimismo, es también favorable a una redistribución vertical de competencias entre los tres grandes niveles (UE, estados y regiones), pero ésta debe estar presidida por una aplicación del principio de subsidiariedad más favorable que la actual a las entidades subestatales. En todo caso, la prioridad clave debe ser para CiU la de «dar voz» a Cataluña como tal, es decir, estar presente en las máximas instituciones decisorias de la UE.

El SNP - muy en consonancia con el espíritu general difuso a nivel británico, aunque esta real coincidencia objetiva pueda incomodarle - rechaza el TCUE por afectar negativamente, en su percepción, a los intereses escoceses. Para el SNP, no es necesario incrementar los actuales poderes de las instituciones comunitarias, pues la clave estaría en la subsidiariedad regional.

También la LN rechaza el TCUE, por considerarlo la antesala de un neocentralismo laminador de los derechos de los pueblos y un proyecto de oscu- 
ras élites no representativas. Por tanto, no sería necesario ampliar los poderes de las instituciones de la UE y más bien habría que redistribuir las competencias, a fin de que las regiones incrementaran sustancialmente su protagonismo.

\section{Cuadro 3}

Sí al TCUE

No al TCUE

Ampliar los poderes comunitarios

No ampliar los poderes comunitarios
$\mathrm{CiU}$

SNP, LN

$\mathrm{CiU}$

SNP, LN

\subsection{Las politicas de los tres pilares}

\subsubsection{Economía y sociedad}

Los criterios económicos de CiU preconizan adoptar políticas conjuntas para reforzar el mercado único europeo, la productividad, la competitividad, la reducción de las «cargas fiscales», la flexibilidad y el fomento del espíritu empresarial; todo ello dentro de los parámetros del Pacto de Estabilidad, que no puede ser incumplido de forma unilateral. No por casualidad, la parte mucho más extensa y detallada del programa de esta formación es precisamente la dedicada a la integración económica, un objetivo apoyado de forma contundente que refleja tanto la ideología de la misma, como lo que más le interesa de la actual UE, ya que es en este ámbito donde ésta ha ido más lejos. Para CiU, «hay que eliminar las barreras comerciales y abrir los mercados de la UE», en aras de potenciar al máximo las cuatro grandes libertades comunitarias. Aunque $\mathrm{CiU}$ está a favor de una mayor armonización de las políticas fiscales de los estados, añade que «hay que simplificar y aligerar las cargas administrativas y fiscales que recaen en las pequeñas y medianas empresas» y en la actividad productiva en general. Asimismo, aunque se asume la necesidad de fomentar políticas de plena ocupación, se precisa que ello debe hacerse dentro de «un marco de relaciones laborales más flexible». Especial hincapié hace CiU en esta premisa, al defender que hay que «avanzar hacia la creación de un modelo europeo de relaciones laborales de carácter flexible, a fin de eliminar determinadas rigideces en el funcionamiento de los mercados de trabajo». Todo en completa sintonía con los intereses de un empresariado cada vez más reacio a seguir sosteniendo un determinado modelo de Welfare State heredado de otras coyunturas en las que los agentes sociales pactaron ciertas transacciones compensatorias reputadas hoy "antieconómicas». Pese a este discurso neoliberal, CiU se muestra favorable al mantenimiento de fondos comunitarios: «la ampliación de la UE no puede suponer la supresión total de los Fondos de Cohesión para el Estado español».

En principio, $\mathrm{CiU}$ asume con carácter general el modelo social europeo, pero añade que éste "necesita adaptarse», un eufemismo para indicar recortes públicos sin formalizarlo. Por ejemplo, el epígrafe del programa de CiU sobre pensiones se subtitula muy significativamente «un problema europeo» y en él se 
defiende la necesidad de abrir un debate «sereno», pues — a su juicio- es necesario «adaptar» $\mathrm{y}$ «reformar» el actual modelo reputado, en el fondo, insostenible para los intereses empresariales y financieros privados. En políticas concretas, $\mathrm{CiU}$ reconoce que la PAC deberá ser sustituida progresivamente para desregularla y orientarla al mercado, con eliminación gradual de subsidios y ayudas a la exportación. Del mismo modo, la PCC deberá hacerse más flexible, sin merma de mantener ciertas cuotas esenciales para el Estado español. $\mathrm{CiU}$ preconiza, asimismo, una protección medioambiental «flexible», lo que — en la práctica - equivale a anularla. Su fórmula es la siguiente: «hay que establecer unos derechos ambientales comunes para todos los ciudadanos europeos, pero flexibilizar su aplicación en el territorio», una reserva que en la España autonómica sólo beneficia, por ejemplo, a la especulación urbanística y al desmedido crecimiento inmobiliario. Esta formación admite el principio de la responsabilidad medioambiental («el que contamina, paga»), pero añade una nueva reserva que dificulta sobremanera su exigibilidad efectiva: «creemos que no se ha de permitir que este principio paralice la innovación y las nuevas actividades emprendidas en la UE». Incluso en un asunto cada vez más vital para la humanidad prevalece al final la óptica privatista: hay que reducir la emisión de gases que aumente el efecto invernadero, "pero lo haremos de manera flexible», lo que —a efectos prácticos - convierte tal proclama en retórica. Es más, CiU añade que habrá que otorgar permisos de emisión necesarios para que la industria pueda asegurar su grado de actividad y crecimiento sin que haya un proceso de deslocalización por motivos energéticos, con lo que debe primar el interés y el beneficio inmediato de las empresas sobre el bienestar de las personas y la preservación del medioambiente. En este programa, se menciona nada menos que tres veces el faraónico y no justificado proyecto de trasvase del Ródano, una vieja obsesión de CiU que responde tanto a un interés político (depender un poco menos de las cuencas españolas al respecto) como - sobre todo- empresarial (hay poderosos lobbies privados muy interesados en tal obra). Finalmente, en I+D, CiU propone incrementar su presupuesto en la UE hasta el 3\% del PIB antes de 2010 y hacerlo con determinada óptica privatista: «las prioridades investigadoras tendrán que combinar las consideraciones comerciales, políticas y académicas, procurando [sic, no se dice "impidiendo"] que los criterios de financiación no acaben con la libertad y la independencia académica». Para CiU es clave vincular las universidades a las empresas, así como promocionar el espíritu empresarial, de ahí que —a su juicio- sea preciso «incorporar la formación en materia de creación de empresas en el sistema educativo [...] para priorizar la cultura de la asunción del riesgo». Todo un programa para impulsar el desarrollo general de una mentalidad capitalista y para subordinar la enseñanza a los imperativos últimos del mercado.

El SNP se muestra favorable a preservar el modelo social europeo y el medioambiente, siempre con la constante remisión a los intereses de Escocia como eje exclusivo de su actuación. Así, por ejemplo, se afirma que Escocia produce mucha energía (petrolífera, eólica, del mar), pero no se beneficia como debiera dado el «expolio» británico. A continuación, se exigen más derechos 
sociales para los trabajadores, bloqueados por el Reino Unido a causa de sus cláusulas de opting-out en materia. El SNP se muestra favorable al euro, algo que deberá decidirse mediante referéndum, pero — una vez más - el problema radicaría en el hecho de que el proceso lo controla Londres. La parte más detallada del programa del SNP en este capítulo es la dedicada a la PCC, a la que se opone rotundamente porque — desde su perspectiva - es lesiva para la pesca y la industria pesquera escocesas. El SNP se presenta como el único defensor de los intereses escoceses en este ámbito y argumenta que todo él debería estar determinado por Escocia, no por la UE. A su juicio, el Gobierno británico habría "traicionado» a los pescadores y a la industria pesquera escocesa, pues la PCC es reputada desastrosa por el SNP. Es más, la PCC sólo sería beneficiosa para países como España, que, al mismo tiempo, apenas aportan algo en recursos pesqueros: los pescadores españoles esquilmarían los caladeros escoceses sin contrapartidas, de ahí que el SNP reclame firmemente el control regional integral de este sector.

La LN ha atenuado su radical liberismo (este neologismo italiano designa la defensa de un sistema económico liberal, pero no la proyección de este enfoque a otros ámbitos) inicial, siempre dentro de su concepción proteccionista y de sintonía con cierto tipo de PYME del norte de Italia. Así, de un lado, rechaza la apertura irrestricta de los mercados, la supresión de aranceles aduaneros, la rigidez del Pacto de Estabilidad, la disciplina del euro con relación a las ayudas del estado a las empresas o las reglamentaciones «invasivas», pues, a su juicio, todo ello no haría más que favorecer a las multinacionales, al diseño del superestado europeo y, en definitiva, a los intereses de la globalización. De otro, esta formación está a favor de incrementar los subsidios a las empresas y a la producción local con una interpretación menos rigurosa que la de la Comisión del concepto de «ayudas estatales» y una mayor descentralización regional. Para la LN, el euro ha sido una imposición antipopular y las obsesiones reguladoras de muchos dirigentes comunitarios estarían frenando la competencia y, peor, haciendo la vista gorda frente a las empresas de los PECO ante sus menores estándares de calidad productiva. En políticas concretas, la LN rechaza el gran poder de homologación de productos agrícolas de las grandes corporaciones, que van en perjuicio de los intereses locales y los pequeños campesinos, pues las lógicas del mercado global erosionan la identidad regional; todo muy en consonancia con su aspiración a encarnar los intereses de las capas medias productivas. En materia medioambiental, se parte de una afirmación sorprendente, próxima a la de los ecologistas, que supone una notable rectificación de su tradicional liberismo ilimitado: «no hay que subordinar la tutela medioambiental a las exigencias del libre comercio indiscriminado e irracional», por ello su respuesta es la de la atribución regional de tal política. Por último, no pueden ser más conservadoras sus tesis sobre la familia: «los pueblos del norte de Europa no valorizan la familia, que, en cambio, para los pueblos italianos, representa la célula social primaria del bienestar común». Para la LN, la familia «natural» (sic) es el núcleo básico de la sociedad, de ahí que - a su juicio- las recomendaciones europeas sobre las uniones homose- 
xuales y la igualación de las parejas de hecho a los matrimonios formales sean invasivas de los principios y los valores fundamentales de los «pueblos padanos» (sic). Todo ello con consideraciones muy alarmistas sobre el bajo índice de natalidad europea y los riesgos de recurrir a los extracomunitarios para compensar tal déficit, muy de acuerdo con criterios étnicos excluyentes y tendencialmente xenófobos.

Es CiU la formación más decididamente favorable a la máxima liberalización del mercado dentro de parámetros neoliberales, con tres matices: el mantenimiento de un cierto nivel de asistencialismo social paliativo, una óptica de subsidiariedad regional y la continuidad en la recepción de fondos comunitarios. En todo caso, su posición es —en líneas generales - la de ADLE: más mercado y menos estado, más privatizaciones y menos sector público, más desregulaciones y menos intervencionismo dirigista.

El SNP se muestra favorable a mantener y reforzar la Europa social, aunque con una clara perspectiva de prioridad nacional. En todo caso, opta por un modelo de economía mixta, con regulaciones y prestaciones asistenciales públicas que quiere ubicarse en el espacio del centro-izquierda.

La LN ha atemperado considerablemente su visión ultraliberal y, en este manifiesto, se muestra favorable a ciertas regulaciones y prestaciones, siempre con una clara salvedad: la protección de los sectores sociales de las capas medias productivas del norte de Italia a las que este partido aspira a representar.

\section{Cuadro 4}

UEM irrestricta

UEM = liberalización parcial con proteccionismo territorial

UEM = liberalización parcial con compensaciones sociales

LN

$\mathrm{UEM}=$ liberalización con recepción de fondos comunitarios

SNP

$\mathrm{CiU}$

\subsubsection{La PESC/ PESD}

$\mathrm{CiU}$ se muestra favorable a unificar la voz internacional de la UE, pues, a su juicio, ésta «deberá sustituir a sus estados miembros como miembro permanente del Consejo de Seguridad de Naciones Unidas». Esta formación es partidaria de una PESD común dentro de la OTAN y a una PESC que "no puede quedar fuera del control democrático del Parlamento europeo».

El SNP apuesta por reforzar el segundo pilar desde una perspectiva multilateral, a fin de que la UE tenga capacidad de prevenir conflictos y pueda impulsar procesos de paz. A su juicio, la UE debe tener una mayor presencia internacional en consonancia con su poder económico y, además, con énfasis en la necesidad de incrementar las ayudas al desarrollo. En realidad, el SNP — aunque no pueda reconocerlo abiertamente- está muy influido por la visión británica de la UE, de ahí que no cuestione en absoluto el actual modelo de la OTAN.

La LN no hace la menor referencia a estas cuestiones en su programa europeo, lo que no deja de ser un tanto significativo, pues refleja su absoluto desinterés por un pilar que, de integrarse más, podría ir forjando la perspectiva federalizante, que es, precisamente, la que tal partido rechaza. 
En suma, tanto CiU como el SNP, aunque favorables a reforzar el segundo pilar de la UE, tienen una óptica atlantista sin merma de cierta capacidad europea autónoma en su seno.

\section{Cuadro 5}

\begin{tabular}{ll}
\hline PESC/PESD $=$ Estados + OTAN & - \\
PESC/PESD $=$ UE y OTAN & CiU, SNP \\
PESC/PESD $=$ UE antes que OTAN & - \\
No consta & LN \\
\hline
\end{tabular}

\subsubsection{De la CAJI al ELSJ}

CiU se limita a señalar, muy brevemente en este ámbito, la necesidad de reforzar Europol — sin más concreciones-y de armonizar el derecho penal.

Al SNP lo único que le importa en las materias del tercer pilar es que la lucha contra el terrorismo y el crimen organizado no vaya en detrimento del distintivo sistema legal escocés, un planteamiento estrictamente nacionalista del todo anacrónico (e ineficaz) en una UE muy vulnerable a tales fenómenos, para cuyos actores las fronteras no existen y las fragmentaciones policiales y penales son incluso una ayuda.

En este ámbito, hay, en el programa de la LN —-bastante detallado al respecto, lo que es muy significativo-, una verdadera obsesión por los peligros del terrorismo (islamista, en particular), reputado la mayor amenaza para el mundo occidental, pues, en su opinión, «es la contraposición entre el oscurantismo y el fanatismo y los valores de las democracias avanzadas». En este sentido, para este partido, la UE debe concentrarse en la lucha contra el terrorismo, el crimen organizado y la inmigración irregular, la habitual tríada acumulada de forma interesada: "la lucha contra el terrorismo está estrechamente vinculada a los fenómenos de apertura de fronteras, de incremento de los intercambios y de la inmigración». Sentado este diagnóstico, las recetas que se proponen son las de reforzar los controles de las fronteras exteriores y ampliar al máximo la cooperación policial al respecto. Sin embargo, a continuación se añaden tesis contradictorias con tal objetivo, ya que la LN está en contra de la progresiva unificación penal europea, pues — a su juicio - restringiría las garantías, sin aportar la menor prueba en este sentido. Así, se rechazan la euroorden o el fiscal europeo, desde el momento en que podrían suponer la imposición, a un ciudadano de un estado, de una pena en otro por un delito que no sería tal en su país (una hipótesis más teórica que real). En efecto, en opinión de este partido, tales medidas irían en la dirección de un superestado europeo, un escenario que la LN rechaza totalmente. Por tanto, para evitar tales intrusiones comunitarias, sería fundamental reforzar el principio de subsidiariedad a favor de los estados y las regiones.

En materias del tercer pilar, sorprende la parquedad de CiU, aunque es la formación más favorable a una mayor comunitarización del mismo. En cambio, el SNP y la LN mantienen típicas posiciones intergubernamentales, con rotundo rechazo en el caso del segundo partido de ceder soberanía a la UE, y 
eso pese a su denuncia muy alarmista de los muy graves riesgos representados por el terrorismo internacional, toda una contradicción.

\section{Cuadro 6}

\begin{tabular}{ll}
\hline ELSJ intergubernamental & SNP, LN \\
ELSJ intergubernamental con mayor cooperación comunitaria & CiU \\
ELSJ supranacional & -
\end{tabular}

\section{Conclusiones provisionales}

Del análisis transversal comparado de los programas de estas tres formaciones, se desprenden algunas coincidencias y bastantes más divergencias en la mayoría de las cuestiones escogidas, lo que prueba la diversidad de las estrategias europeístas de los PANE7 . Una mera cuantificación objetiva de las posiciones analizadas en esta investigación que no discrimine los ítems en función de las preferencias políticas e ideológicas específicas de cada partido, muestra que la formación que mantiene más posiciones singulares es CiU, seguida del SNP y la LN, por este orden. Que CiU coincida algo más con el SNP que con la LN entra dentro de lo previsible a priori, pero no así que estos dos últimos partidos - muy distintos ideológicamente-coincidan en varias issues. Es evidente que, más allá de las coincidencias objetivas transversales — en sí mismas, poco indicativas - las claves están en las diferencias cualitativas sobre diversos asuntos de fondo ya examinados ${ }^{8}$.

La formación más favorable a una mayor integración comunitaria es CiU, ya que, tanto el SNP como la LN, rechazan que la UE pueda intentar siquiera rebasar un horizonte estratégico de carácter confederal. Incluso CiU mantiene una calculada ambigüedad sobre el diseño final de la UE, pues la indefinición da más juego político. El SNP es el que más defiende una perspectiva intergubernamental de corte estatalista clásico, puesto que su programa aspira a conseguir el estatus de estado formalmente independiente como nuevo miembro de la UE. La LN es mucho menos precisa, tanto por su habitual oportunismo a la hora de dosificar un inconcreto federalismo para Italia, como por recurrir a amenazas más o menos veladas de secesión, como por el carácter artificial del territorio que aspira a representar (la quimérica "Padania»). Por su parte, CiU traspone a nivel comunitario su estrategia de intervencio-

7. Aguilera de Prat, C. R. «De la "Europa de las Regiones" a la Europa con las Regiones». Revista d'Estudis Autonómics $i$ Federals, n. o 2, 2006, p. 58-60. KEATING, M. "La integración europea y la cuestión de las nacionalidades». Revista Española de Ciencia Política, n. ${ }^{o}$ 16, abril de 2007, p. 13-14 y 21.

8. El entrecruzamiento de los seis cuadros produce los siguientes resultados: CiU mantiene una posición singular en seis asuntos, coincide con el SNP en tres y con la LN en dos. El SNP mantiene una posición singular en cuatro asuntos, coincide con $\mathrm{CiU}$ en tres y con la LN en cuatro. La LN mantiene una posición singular en tres asuntos, coincide con CiU en uno y con el SNP en cuatro. 
nismo español sin concretar modelo final alguno y siempre con objeto de conseguir el máximo autogobierno posible, sin formalizar una apuesta independentista. De resultas de todo ello, el SNP y la LN consideran más que suficiente el nivel competencial alcanzado por las instituciones comunitarias y sólo $\mathrm{CiU}$ se inclina por seguir ampliando sus poderes dentro de un esquema tendencialmente parlamentario.

En cuestión de fronteras exteriores, CiU y la LN se inclinan por ir perfilando el debate definitivo sobre las mismas, a fin de tomar una decisión de cierre a medio plazo. En el caso concreto de Turquía, el rechazo de la LN es frontal y, para ello, recurre preferentemente a argumentos históricos y culturales por encima de razones políticas y económicas. Es muy significativo, en cambio, que el SNP no se pronuncie ni sobre las fronteras exteriores de la UE definitivas ni sobre la candidatura turca, ya que, en el fondo, sintoniza con las mayoritarias posiciones de los partidos británicos, favorables a mantener abiertas las incorporaciones y, en particular, la de Turquía.

La LN no otorga ninguna virtualidad sustantiva a la noción de "ciudadanía europea», mientras que CiU y el SNP la aceptan como mero complemento derivado de la nacionalidad propia. Sólo la LN defiende la tesis de formalizar las «raíces cristianas» en la UE, CiU no se pronuncia y el SNP —un partido estrictamente laico- apuesta por la sociedad multicultural dentro de la Scottishness. Esto tiene consecuencias con relación a sus opciones migratorias, pues la LN es contraria a las mismas, CiU las acepta pero con cupos controlados y sólo el SNP no pone límites al respecto, también muy en consonancia con las peculiaridades británicas, por cierto.

Sólo CiU da pleno apoyo al TCUE (pese a su carácter estatalista, pero ello también es congruente, pues esta federación es autonomista, no independentista), mientras que el SNP y la LN lo rechazan: el primero precisamente por consagrar a los actuales estados que niegan el derecho de autodeterminación y el segundo partido por representar una «amenaza» potencial de carácter federalizador (el «superestado» europeo). Por tanto, sólo CiU es favorable a incrementar los poderes institucionales comunitarios, mientras que el SNP y la LN se oponen a seguir ampliándolos.

En políticas del primer pilar, quedan claras las preferencias ideológicas de cada uno, más o menos matizadas por las características de sus territorios. Por ejemplo, CiU y la LN siempre han sido decididamente favorables a reforzar al máximo el mercado y reducir el papel del estado en la economía, pero los nacionalistas conservadores catalanes no renuncian a seguir recibiendo fondos comunitarios y los liguistas (antes neoliberales irrestrictos) han optado ahora por políticas proteccionistas para los "propios». El SNP, en consonancia con su orientación de centro-izquierda, sólo apoya la integración económica y monetaria de la UE a cambio de significativas contraprestaciones sociales redistributivas.

En materias del segundo pilar, ninguno preconiza configurar un sistema europeo de defensa separado de la OTAN (la LN no se pronuncia en todas estas cuestiones) y tanto $\mathrm{CiU}$ como el SNP preconizan el máximo entendimiento y colaboración entre los Estados Unidos de América y la UE. Por últi- 
mo, en asuntos del tercer pilar, tanto el SNP como la LN comparten una visión intergubernamental clásica, mientras que CiU sí se muestra favorable a ceder competencias soberanas en este ámbito a la UE.

\section{Siglas}

CAJI / ELSJ: Cooperación en Asuntos de Justicia e Interior / Espacio de Libertad, Seguridad y Justicia.

PAC: Política Agrícola Común.

PCC: Política Pesquera Común.

PE: Parlamento europeo.

PECO: Países de Europa Central y Oriental.

PESC / PESD: Política Exterior y de Seguridad Común / Política Europea de Seguridad y Defensa.

UEM: Unión Económica y Monetaria.

\section{Obras de referencia sobre los partidos analizados}

Convergència i Unió:

Aguilera de Prat, C. R. (2002). Partidos y estrategias nacionalistas en Cataluña, Escocia y Flandes. Valencia: Tirant lo Blanch.

CAMINAL, M. (1998). Nacionalisme i partits nacionals a Catalunya. Barcelona: Empúries.

Culla, J. B. (coord.) (2001). El pal de paller: Convergència Democràtica de Catalunya (1974-2000). Barcelona: Pòrtic.

MARCET, J. (1987). Convergència Democràtica de Catalunya: el partido y el movimiento politico. Madrid: CIS-Siglo XXI.

Scottish National Party

Brand, J. A. (1978). The National Movement in Scotland. Londres: Mac Millan. Brown, A.; Mac Crone, D.; Paterson, L. (1998). Politics and Society in Scotland. Londres: Mac Millan.

LYNCH, P. (2002). The SNP: A History of the Scottish National Party. Cardiff: Welsh Academic Press.

Moreno, L. (1995). Escocia, nación y razón: Dos milenios de política y sociedad. Madrid:

CSIC.

Lega Nord

Aguilera de Prat, C.R. (1999). El cambio político en Italia y la Liga Norte. Madrid: CIS.

Biorcio, R. (1997). La Padania promessa: La storia, le idee e la logica d'azione della Lega Nord. Milán: Il Saggiatore.

Diamanti, I. (1995). La Lega. Geografia e sociologia di un soggetto politico. Roma: Donzelli.

Gómez-Reino, M. (2002). Ethnicity and Nationalism in Italian Politics. Inventing the Padania: Lega Nord and the Northern Question. Aldershot. Ashgate. 